\title{
Focal segmental glomerulosclerosis, excluding atypical lesion, is a predictor of renal outcome in patients with membranous nephropathy: a retrospective analysis of 716 cases
}

Hong-Guang He', Chao-Qing Wu ${ }^{1}$, Kun Ye ${ }^{1}$, Chun Zeng ${ }^{1}$, Yi-Yun Huang ${ }^{1}$, Shu-Wen Luo' ${ }^{1}$ Wu Yin², Qiu-Rong $\mathrm{Ye}^{2}$ and Xiao-Mei Peng ${ }^{1^{*}}$

\begin{abstract}
Background: Focal segmental lesions (FSLS) are not uncommon in idiopathic membranous nephropathy (IMN). The reported percentage of IMN patients with focal segmental glomerulosclerosis (FSGS) lesions varies widely between studies. The objective of this study was to differentiate atypical FSL (aFSL) from typical FSGS in IMN and to analyse the clinicopathological predictors of primary outcome of IMN patients.

Methods: A total of 716 patients with biopsy-proven IMN between January 1, 2007 and December 31, 2017 were enrolled in the study. An atypical focal segmental lesion was defined as pure synechia, segmental hyperplasia of podocytes or thickening of the GBM accompanied by proliferation of the mesangial matrix, and absence of typical FSGS. The patients were divided into three groups: patients without FSL (FSL'), patients with typical FSGS (FSGS ${ }^{+}$), and patients with aFSL (aFSL ${ }^{+}$.The primary outcome was a 50\% decline in the initial estimated glomerular filtration rate or end-stage renal disease (ESRD) incidence. Secondary outcomes included all-cause death and ESRD.
\end{abstract}

Results: FSGS was present in 174 patients, while aFSL was noted in 161 patients. Systolic blood pressure was higher in both $\mathrm{aFSL}^{+}$group and $\mathrm{FSGS}^{+}$groups compared with the $\mathrm{FSL}^{-}$group. IMN patients without FSL and with aFSL had lower serum creatinine levels than IMN patients with FSGS. Both the $\mathrm{FSGS}^{+}$and $\mathrm{aFSL}^{+}$groups had higher levels of proteinuria and lower albumin levels than the $\mathrm{FSL}^{-}$group. Renal tissue lesions, including tubulointerstitial fibrosis, glomerular obsolescence, and vascular sclerosis were significantly more severe in the $\mathrm{FSGS}^{+}$group. Cox multivariate analysis showed that older age $\geq 60$ years, eGFR $<60 \mathrm{ml} /\left(\mathrm{min} \cdot 1.73 \mathrm{~m}^{2}\right)$, tubulointerstitial fibrosis area $\geq 15 \%$ and FSGS at biopsy were independent risk factors for the primary outcome.

Conclusions: No significant difference in outcome was found between the $\mathrm{FSL}^{-}$and $\mathrm{aFSL}^{+}$groups, although the patients with aFSL had lower levels of serum albumin and eGFR, higher level of urinary protein, more severe renal lesions with proliferation of the mesangial area,tubulointerstitial fibrosis and vascular sclerosis. FSGS, excluding atypical lesions, was an independent predictor of the primary outcome.

Keywords: Idiopathic membranous nephropathy, Focal segmental glomerulosclerosis, Prognostic factors, Pathology, Atypical focal segmental lesion

\footnotetext{
* Correspondence: mei6286@126.com

1Department of Nephrology, The People's Hospital of Guangxi Zhuang

Autonomous Region, 6 Taoyuan Road, Qingxiu District, Nanning 530000,

China

Full list of author information is available at the end of the article
}

(c) The Author(s). 2019 Open Access This article is distributed under the terms of the Creative Commons Attribution 4.0 International License (http://creativecommons.org/licenses/by/4.0/), which permits unrestricted use, distribution, and reproduction in any medium, provided you give appropriate credit to the original author(s) and the source, provide a link to the Creative Commons license, and indicate if changes were made. The Creative Commons Public Domain Dedication waiver (http://creativecommons.org/publicdomain/zero/1.0/) applies to the data made available in this article, unless otherwise stated. 


\section{Background}

Idiopathic membranous nephropathy (IMN) is one of the most common causes of adult-onset nephrotic syndrome both in Caucasian and the Chinese individuals [1,2], and China has witnessed an increasing prevalence of IMN among patients with primary glomerulonephritis, from $7 \%$ in $1997-1999$ to $23 \%$ in 2009-2011 [2]. In 1977, Ehrenreich and Churg [3] observed lesions of focal sclerosis in cases of membranous nephropathy (MN), and some studies have indicated that focal segmental glomerulosclerosis (FSGS) is a risk factor for poor prognosis or an independent indicator of poor prognosis [4-8]. An international group of renal pathologists convened at Columbia University to reach a consensus regarding the pathologic classification of FSGS [9]; however, whether FSGS is an independent predictor in IMN remains unresolved [10-13]. The percentage of IMN patients with FSGS lesions differs in the literature, ranging from 2.5 to $41.7 \%$ [4, 7, 12-15], and in addition to geographical distribution, enrolment methods and ethnicity, the different definitions of FSGS lesions in IMN used in clinical practice may account for this variability.

In previous studies, segmental lesions in IMN included perihilar, not-otherwise specified (NOS), and tip variant [7], while the atypical segmental lesion (aFSL) described in the present study, which includes synechia [4], segmental hyperplasia of podocytes, and segmental glomerular basement membrane (GBM) thickening and/or with proliferation of mesangial matrix of the segmental tuft is also commonly seen in IMN.

In this study, we aimed to differentiate atypical focal segmental lesion (aFSL) from typical FSGS in IMN, ascertain the clinicopathological characteristics of IMN with aFSL, and analyse the clinicopathological characteristics and outcomes of IMN patients with aFSL and FSGS.

\section{Methods}

\section{Patient selection}

We included patients with a diagnosis of IMN, who are biopsied between January 1, 2007 and December 31, 2017 in our hospital, excluding patients with diagnoses such as lupus nephritis, MN related to hepatitis B virus, malignancy, metal poisoning, or other diseases associated with secondary MN. The enrolled patients were treated with angiotensin-converting enzyme (ACE) inhibitors or angiotensin receptor blockers, corticosteroids, cyclophosphamide, cyclosporine, tacrolimus, azathioprine, Tripterygium wilfordii [16], and mycophenolate mofetil. All patients were $\geq 14$ years of age at the time of renal biopsy. All renal biopsies were evaluated by light and immunofluorescence microscopy, ultrastructural evaluation was performed if necessary. Follow-up started at the time of biopsy and either continued until December 2018 or ended at the time of death or development of end-stage renal disease (ESRD).

\section{Clinical parameters}

For the enrolled patients, age, sex, duration of disease before biopsy, levels of serum creatinine and albumin, 24-h proteinuria content, systolic and diastolic blood pressures were recorded at the time of biopsy.

The Chronic Kidney Disease Epidemiology Collaboration (CKD-EPI) equation was used to estimate glomerular filtration rate (eGFR) [17]. The CKD was classified based on the KDIGO 2012 Clinical Practice Guideline [18]. Hypertension was defined as blood pressure exceeding 140 over 90 $\mathrm{mmHg}$ or currently receiving antihypertensive therapy.

\section{Histopathologic parameters}

Renal biopsy specimens including at least eight glomeruli were analysed in this study. Renal tissue specimens were examined by two pathologists with no knowledge of the patients' clinical condition to establish the diagnosis by standard pathologic methods alone. The pathological features under light microscopy, stage, global sclerosis, segmental sclerosis, tubulointerstitial fibrosis, and arteriosclerosis were collected. FSL was graded as present or absent, including FSGS and aFSL. AFSL was defined as follows: 1) pure synechia (Fig. 1a), and synechia at the tip pole, and/or accompanied by proliferation of matrix (Fig 1b) also was also classified in aFSL in present study; 2) Hyperplasia of podocytes (Fig. 1c, arrow), which may be accompanied by segmental thickening of the GBM or proliferation of mesangial matrix; 3) Proliferation of the extracellular matrix of the segmental tuft (Fig. 1d, f), or thickening of the GBM (Fig. 1e); often accompanied by segmental endothelial cell hyperplasia (Fig. 1 e, f); and 4) absence of typical FSGS, with no accumulation of inframembranous hyaline, no collapsing tuft, and without foam cells occluding the lumina. FSGS lesions were categorized according to the Columbia FSGS classification system [9], but synechia at the tip pole (and/ or accompanied with proliferation of matrix), was classified as aFSL in the present study, in order to coincide with the definition of other locations..

Based on this classification, the subjects were divided into three groups: patients without focal segmental lesion $\left(\mathrm{FSL}^{-}\right)$, with FSGS $\left(\mathrm{FSGS}^{+}\right)$, and with aFSL,but not co-occurring with FSGS $\left(\mathrm{aFSL}^{+}\right)$. Tubulointerstitial fibrosis was defined as increased extracellular matrix separating tubules in the cortical area and was recorded according to the area of fibrosis. The score for degree of vascular sclerosis was based on the most severe lesion seen in either arterioles or arteries [11]. 


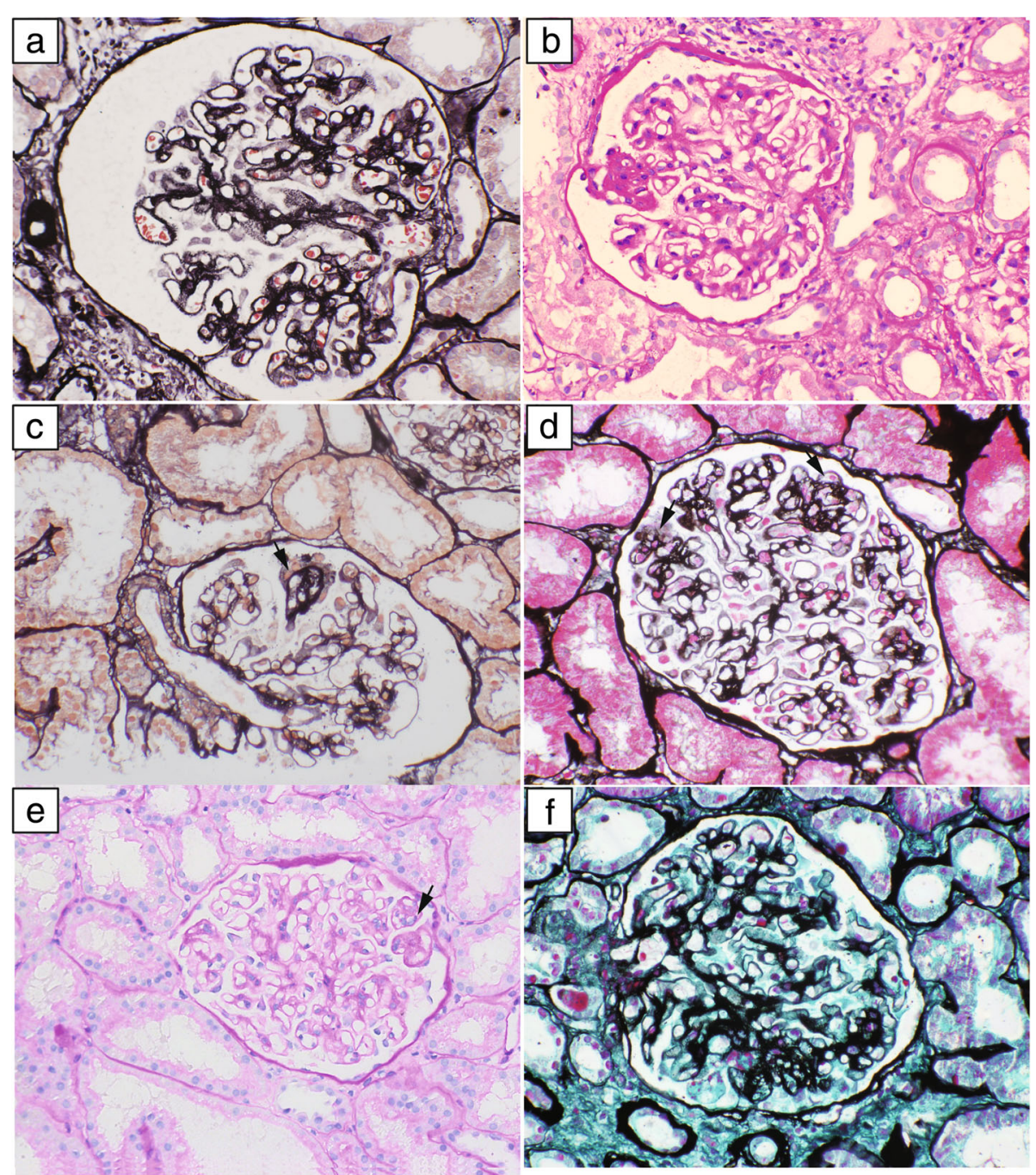

Fig. 1 Early focal segmental lesions in IMN patients: a Pure synechia to Bowman's capsule,with glomerular enlargement;(PASM;original magnification $\times 400$.) b Synechia at the tip area,accompanied with proliferation of mesangial matrix; (PAS; original magnification $\times 400$.) $\mathbf{c}$ Segmental thickening of GBM, accompanied with hyperplasia of podocytes (arrow); (PASM; original magnification× 400.) $\mathbf{d}$ Proliferation of extracellular matrix of segmental tuft, with slight hyperplasia of podocytes and proliferation of endothelial cells (arrows);(PASM;Original magnification× 400.) e Segmental thickening of GBM,accompanied with segmental proliferation of endothelial cell (arrow); (PAS; Original magnification $\times 400$.) $\mathbf{f}$ Segmental proliferation of extracellular matrix of segmental tuft, with hyperplasia of podocytes and proliferation of endothelial cells.(PASM; original magnification× 400)

\section{Study outcomes}

The primary end point was the composite of ESRD (defined by persistent eGFR $<15 \mathrm{ml} / \mathrm{min}$ per $1.73 \mathrm{~m}^{2}$, start of chronic dialysis, or preemptive kidney transplantation) or a $50 \%$ reduction in eGFR over followup. Secondary outcomes included all-cause death, and ESRD.

\section{Statistical analysis}

Normally distributed variables were expressed as the mean \pm standard deviation and compared using oneway analysis of variance. Nonparametric continuous variables were expressed as medians (interquartile ranges) and compared using the Kruskal-Wallis test. Categorical variables were expressed as percentages and compared using the $x^{2}$-test or Fisher exact test. The cumulative probabilities of event-free survival for outcomes were determined using the Kaplan-Meier method and log-rank tests. The independent risk factors for outcomes were analysed with the Cox proportional hazards model. All $P$-values were two-tailed and values $<0.05$ were considered to indicate statistical significance. The confidence interval included $95 \%$ of predicted values. Statistical analyses were performed using SPSS statistical software (version 23.0, SPSS, Chicago, IL). 


\section{Results}

\section{Baseline characteristics}

A total of 716 patients with IMN were included in this study. The mean age at diagnosis was $49 \pm 14$ years and the median follow-up was 20(interquartile range:8-35) months. The median serum creatinine level was 77(interquartile range:62-91) $\mu \mathrm{mol} / \mathrm{L}$. There were 68 patients with an eGFR of $<60 \mathrm{~mL} / \mathrm{min}$ per $1.73 \mathrm{~m}^{2}$ and 388 with an eGFR of $>90 \mathrm{~mL} / \mathrm{min}$ per $1.73 \mathrm{~m}^{2}$.The median proteinuria value was $4.8 \mathrm{~g} /$ day (interquartile range: $2.7-7.5 \mathrm{~g} /$ day), and 150 patients had proteinuria of $>8.0 \mathrm{~g} /$ day.
A comparison of demographic and baseline clinicopathological data among the $\mathrm{FSGS}^{+}, \mathrm{aFSL}^{+}$, and $\mathrm{FSL}^{-}$ IMN patients is summarized in Table 1. FSGS was present in 174 patients, while aFSL was noted in 161 patients. Compared with $\mathrm{FSL}^{-}$and $\mathrm{aFSL}^{+}$patients, patients with combined FSGS lesions had higher systolic blood pressure, diastolic blood pressure, and serum creatinine level and a lower GFR. Compared with the $\mathrm{FSL}^{-}$group, both the $\mathrm{FSGS}^{+}$and $\mathrm{aFSL}^{+}$groups had significantly lower albumin, and higher 24-h urine protein.

Of the 174 patients with FSGS lesions, 70 presented with tip lesions, 73 with NOS lesions, 23 with

Table 1 Comparison of the clinicopathological parameters of patients among the three groups at baseline

\begin{tabular}{|c|c|c|c|}
\hline Parameters & $\mathrm{FSL}^{-}$ & $\mathrm{aFSL}^{+}$ & $\mathrm{FSGS}^{+}$ \\
\hline$n$ & $381(53.2 \%)$ & $161(22.5 \%)$ & $174(24.3 \%)$ \\
\hline Male, n (\%) & $193(50.7 \%)$ & $92(57.1 \%)$ & $109(62.6 \%)^{\dagger}$ \\
\hline Age (years) & $49 \pm 14$ & $48 \pm 15$ & $52 \pm 14^{\dagger \S}$ \\
\hline Age $\geq 60, n(\%)$ & $91(23.9 \%)$ & $40(24.8 \%)$ & $57(32.8 \%)$ \\
\hline $\mathrm{SBP}(\mathrm{mm} \mathrm{Hg})$ & $130(119,147)$ & $136(123,154)^{*}$ & $147(132,162)^{\dagger \S}$ \\
\hline $\mathrm{DBP}(\mathrm{mm} \mathrm{Hg})$ & $80(72,88)$ & $80(74,91)$ & $86(77,95)^{\dagger \S}$ \\
\hline Hypertension, n (\%) & $158(41.5 \%)$ & $86(53.4 \%)$ & $118(67.8 \%)^{\dagger \S}$ \\
\hline Duration of disease before biopsy (months) & $2(1,5)$ & $2(1,7)$ & $4(1,9)^{\dagger}$ \\
\hline Albumin(g/L) & $24.4(20.7,28.9)$ & $21.7(18.5,26.9)^{*}$ & $20.9(17.0,24.4)^{\dagger}$ \\
\hline Urine protein content(g/24 h) & $4.0(2.3,6.6)$ & $5.4(3.4,8.1)^{*}$ & $5.6(3.6,8.8)^{\dagger}$ \\
\hline Serum creatinine $(\mu \mathrm{mol} / \mathrm{L})$ & $72(59,83)$ & $78(64,92)^{*}$ & $85(69,103)^{\dagger \S}$ \\
\hline eGFR $\left(\mathrm{ml} / \mathrm{min}\right.$ per $\left.1.73 \mathrm{~m}^{2}\right)$ & $98(83,110)$ & $91(77,109)^{*}$ & $81(64,102)^{\dagger \S}$ \\
\hline CKD $\geq 3$ stage & $13(3.4 \%)$ & $18(11.2 \%)$ & $37(21.3 \%)^{+\S}$ \\
\hline Immunosuppressants & $289(75.9 \%)$ & $136(84.4 \%)$ & $151(86.8 \%)^{\dagger}$ \\
\hline Stage & & * & $\dagger$ \\
\hline । & $131(34.4 \%)$ & $32(19.9 \%)$ & $26(14.9 \%)$ \\
\hline$\|$ & $214(56.2 \%)$ & $88(54.7 \%)$ & $104(59.8 \%)$ \\
\hline III & $35(9.2 \%)$ & $40(24.8 \%)$ & $42(24.1 \%)$ \\
\hline IV & $1(0.3 \%)$ & $1(0.6 \%)$ & $2(1.1 \%)$ \\
\hline Global glomerulosclerosis (\%) & $0(0,6.3)$ & $2.3(0,8.4)$ & $5.8(0,12.6)^{\dagger \S}$ \\
\hline Proliferation of mesangial area & & * & $+\S$ \\
\hline 0 & $191(50.1 \%)$ & $58(36 \%)$ & $40(23 \%)$ \\
\hline 1 & 171 (44.9\%) & $85(52.8 \%)$ & $106(60.9 \%)$ \\
\hline 2 & $19(5 \%)$ & $17(10.6 \%)$ & $25(14.4 \%)$ \\
\hline 3 & $0(0 \%)$ & $1(0.6 \%)$ & $3(1.7 \%)$ \\
\hline Tubulointerstitial fibrosis(\%) & $2(0,5)$ & $3(2,8)^{*}$ & $8(3,18.5)^{\dagger \S}$ \\
\hline Vascular sclerosis & & & $+\S$ \\
\hline 0 & $105(27.6 \%)$ & $41(25.5 \%)$ & $22(12.6 \%)$ \\
\hline 1 & $211(55.4 \%)$ & $88(54.7 \%)$ & $97(55.7 \%)$ \\
\hline 2 & $56(14.7 \%)$ & $28(17.4 \%)$ & 42 (24.1\%) \\
\hline 3 & $9(2.4 \%)$ & $4(2.5 \%)$ & $13(7.5 \%)$ \\
\hline
\end{tabular}

Abbreviations: SBP Systolic blood pressure, DBP Diastolic blood pressure, eGFR Estimated glomerular filtration rate; Datas are presented as $\mathrm{n}$ (\%), mean \pm s.d. or median (interquartile range)

${ }^{*} P<0.05$ between the $\mathrm{FSL}^{-}$and $\mathrm{aFSL}^{+}$groups; ${ }^{\dagger} P<0.05$ between the $\mathrm{FSL}^{-}$and $\mathrm{FSGS}^{+}$groups ${ }^{\S} P<0.05$ between the aFSL ${ }^{+}$and $\mathrm{FSGS}^{+}$group 
perihilar lesions, 3 with cellular lesions, and 5 with collapsing lesions; Of the 161 patients with atypical focal segmental lesions, 95 presented with synechia lesions,19 with segmental hyperplasia of podocytes (without synechia lesions), and 47 with segmental thickening of GBM, accompanied by proliferation of the mesangial matrix (without hyperplasia of podocytes or synechia lesions).

The percentage of obsolescent glomeruli was highest in the group of patients with FSGS (vs. $\mathrm{FSL}^{-}$group, $P<0.001$; vs. $\mathrm{aFSL}^{+}$group, $P=0.001$ ). A significant increase in the severity of vascular sclerosis lesions was found in biopsy specimens in group $\mathrm{FSGS}^{+}$(vs. $\mathrm{aFSL}^{+}, P=0.002$; vs. $\mathrm{FSL}^{-}$, $P<0.001)$. Furthermore, a significant increase in severe tubulointerstitial fibrosis was also found in biopsy

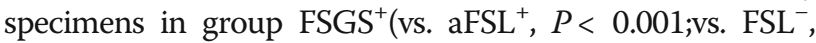
$P<0.001)$ and $\mathrm{aFSL}^{+}$(vs. $\left.\mathrm{FSL}^{-}, P<0.001\right)$. Regarding the staging of membranous lesions, a later stage was observed in the $\mathrm{FSGS}^{+}$group $(P<0.001)$ and in the $\mathrm{aFSL}^{+}$group $(P<0.01)$ compared with the FSL- group (Table 1$)$.

\section{Outcomes}

Two hundred eighty-nine $(75.9 \%)$ patients in the $\mathrm{FSL}^{-}$ group, $136(84.4 \%)$ in the $\mathrm{aFSL}^{+}$group, and $151(86.8 \%)$ in the $\mathrm{FSGS}^{+}$group were treated with immunosuppressive therapy (Table 1). At the end of follow-up, 44 patients (6.1\%) experienced a 50\% decline in eGFR (including progression to ESRD), of which $27(3.8 \%)$ progressed to ESRD. Twenty-four patients (3.4\%) died; causes of death included severe infection (12/25), pulmonary embolism (1/19), and cardio-cerebral vascular events $(11 / 25)$.

The significance of each factor affecting the primary outcome is shown in Table 2 . Among the clinical parameters, old age ( $\geq 60$ years old), hypertension, increased serum creatinine $(\geq 134 \mathrm{umol} / \mathrm{L})$, and eGFR $\left(<60 \mathrm{ml} / \mathrm{min}\right.$ per $\left.1.73 \mathrm{~m}^{2}\right)$ were significant risk factors for primary outcome by univariate analysis. However, male sex, low level of albumin, and high level of 24-h urine protein were not identified as risk factors in our analysis. By univariate analysis, a high incidence of global glomerulosclerosis (present in > $5 \%$ of total glomeruli), and focal segmental lesions (including both atypical focal segmental lesions and typical FSGS lesions), the presence of FSGS lesions alone, tubulointerstitial fibrosis occupying $\geq 15 \%$ of the total specimen area, proliferation of mesangial area, and vascular sclerosis were significant risk factors for primary outcome (Table 2).

By multivariate analysis, in model 1 , old age $(\geq 60$ years old), eGFR $<60 \mathrm{ml} / \mathrm{min}$ per $1.73 \mathrm{~m}^{2}$, tubulointerstitial fibrosis area $\geq 15 \%$ were significant risk factors for progression to primary outcome, while focal segmental lesions (including both atypical focal segmental lesions and typical
Table 2 Univariate analysis of risk factors for progression to primary outcome- Cox proportional hazards model

\begin{tabular}{|c|c|c|c|}
\hline Parameters & $P$ value & $H R$ & $\mathrm{HR}(95 \% \mathrm{Cl})$ \\
\hline Male & 0.199 & 1.505 & $0.806-2.807$ \\
\hline Age $\geq 60$ years & $<0.001$ & 4.430 & $2.406-8.157$ \\
\hline Hypertension & $<0.001$ & 4.591 & $2.134-9.878$ \\
\hline \multicolumn{4}{|l|}{ Albumin(g/L) } \\
\hline$\geq 30$ & & & 1.00 (referent) \\
\hline $20-29.9$ & 0.965 & 1.020 & $0.414-2.517$ \\
\hline$\leq 19.9$ & 0.289 & 1.674 & $0.646-4.339$ \\
\hline \multicolumn{4}{|l|}{ Urine protein content(g/24 h) } \\
\hline$<3.9$ & & & 1.00 (referent) \\
\hline $4-7.9$ & 0.962 & 1.017 & $0.511-2.023$ \\
\hline$\geq 8$ & 0.258 & 1.549 & $0.725-3.311$ \\
\hline Serum creatinine $\geq 134($ umol/L) & $<0.001$ & 16.888 & $8.164-34.932$ \\
\hline eGFR< 60(ml/min per $\left.1.73 \mathrm{~m}^{2}\right)$ & $<0.001$ & 9.509 & $5.178-17.460$ \\
\hline FSL (FSGS,aFSL = 1, $\left.\mathrm{FSL}^{-}=0\right)$ & $<0.001$ & 3.822 & $1.961-7.447$ \\
\hline \multicolumn{4}{|l|}{ FSL } \\
\hline $\mathrm{FSL}^{-}$ & & & 1.00 (referent) \\
\hline FSGS & $<0.001$ & 6.902 & $3.493-13.635$ \\
\hline aFSL & 0.914 & 0.939 & $0.302-2.919$ \\
\hline \multicolumn{4}{|l|}{ Stage } \\
\hline । & & & 1.00 (referent) \\
\hline$\|$ & 0.31 & 1.455 & $0.706-2.998$ \\
\hline III and IV & 0.237 & 1.705 & $0.704-4.133$ \\
\hline Global glomerulosclerosis (> 5\%) & $<0.001$ & 5.212 & $2.680-10.136$ \\
\hline \multicolumn{4}{|l|}{ Proliferation of mesangial area } \\
\hline 0 & & & 1.00 (referent) \\
\hline 1 & 0.034 & 2.095 & $1.059-4.147$ \\
\hline 2 and 3 & 0.061 & 2.741 & $0.956-7.858$ \\
\hline Tubulointerstitial fibrosis (area $\geq 15 \%$ ) & $<0.001$ & 7.368 & $4.050-13.404$ \\
\hline \multicolumn{4}{|l|}{ Vascular sclerosis } \\
\hline 0 & & & 1.00 (referent) \\
\hline 1 & 0.036 & 4.725 & $1.104-20.223$ \\
\hline 2 & 0.002 & 10.617 & $2.440-46.203$ \\
\hline 3 & $<0.001$ & 30.771 & $6.141-154.175$ \\
\hline
\end{tabular}

Abbreviations: HR Hazard ratio, $\mathrm{Cl}$ Confidence interval; Datas are presented as $n(\%)$, or median (interquartile range)

FSGS lesions) was not independent risk factor. However, in model 2 , old age $(\geq 60$ years old $)(\mathrm{HR}, 2.870 ; 95 \% \mathrm{CI}$, $1.519-5.424 ; P=0.001)$, eGFR $<60 \mathrm{ml} / \mathrm{min}$ per $1.73 \mathrm{~m}^{2}$ (HR, 2.925; 95\% CI, 1.441-5.936; $P=0.003$;), FSGS lesions (HR, 2.471; 95\% CI, 1.113-5.486; $P=0.026$ ), tubulointerstitial fibrosis area $\geq 15 \%(\mathrm{HR}, 2.553$; 95\% CI, $1.248-5.224$; $P=0.010)$ were significant independent risk factors for progression to primary outcome (Table 3 ). Twenty-eight patients $(16.1 \%)$ in the $\mathrm{FSGS}^{+}$group reached the primary outcome, compared with 12 patients (3.1\%) in the $\mathrm{FSL}^{-}$ 
Table 3 Mutivariate analysis of risk factors for progression to primary outcome- Cox proportional hazards model

\begin{tabular}{|c|c|c|c|}
\hline Parameters & $P$ value & $\mathrm{HR}$ & $\mathrm{HR}(95 \% \mathrm{Cl})$ \\
\hline \multicolumn{4}{|c|}{ Model 1:FSGS ${ }^{+}$and $\mathrm{FFSL}^{+}$groups as one group (FSL ${ }^{+}$group) } \\
\hline Age $\geq 60$ years & 0.003 & 2.602 & $1.373-4.930$ \\
\hline Hypertension & 0.127 & 1.874 & $0.837-4.192$ \\
\hline eGFR<60(ml/min per $\left.1.73 \mathrm{~m}^{2}\right)$ & 0.009 & 2.632 & $1.279-5.415$ \\
\hline FSL $\left(F S G S, a F S L=1, F^{-}=0\right)$ & 0.251 & 1.557 & $0.731-3.320$ \\
\hline Global Glomerulosclerosis (> 5\%) & 0.278 & 1.548 & $0.703-3.410$ \\
\hline Proliferation of mesangial (stage $1,2,3=1$ ) & 0.648 & 1.178 & $0.582-2.383$ \\
\hline Tubulointerstitial fibrosis (area $\geq 15 \%=1$ ) & 0.003 & 3.008 & $1.470-6.156$ \\
\hline Vascular sclerosis (stage 1,2,3=1) & 0.267 & 2.293 & $0.530-9.921$ \\
\hline \multicolumn{4}{|c|}{ Moldel 2:FSGS ${ }^{+}$and $\mathrm{aFSL}^{+}$groups as two individual groups } \\
\hline Age $\geq 60$ years & 0.001 & 2.870 & $1.519-5.424$ \\
\hline Hypertension & 0.182 & 1.741 & $0.771-3.930$ \\
\hline $\mathrm{eGFR}<60\left(\mathrm{ml} / \mathrm{min}\right.$ per $\left.1.73 \mathrm{~m}^{2}\right)$ & 0.003 & 2.925 & $1.441-5.936$ \\
\hline \multicolumn{4}{|l|}{ FSL } \\
\hline $\mathrm{FSL}^{-}$ & & & 1.00 (referent) \\
\hline FSGS & 0.026 & 2.471 & $1.113-5.486$ \\
\hline aFSL & 0.260 & 0.503 & $0.152-1.663$ \\
\hline Global Glomerulosclerosis (> 5\%) & 0.338 & 1.467 & $0.669-3.215$ \\
\hline Proliferation of mesangial (stage $1,2,3=1$ ) & 0.894 & 1.049 & $0.518-2.122$ \\
\hline Tubulointerstitial fibrosis (area $\geq 15 \%=1$ ) & 0.010 & 2.553 & $1.248-5.224$ \\
\hline Vascular sclerosis (stage 1,2,3=1) & 0.351 & 2.014 & $0.462-8.770$ \\
\hline
\end{tabular}

Abbreviations: HR Hazard ratio, Cl Confidence interval

$\operatorname{group}(P<0.001)$ and 4 patients $(2.5 \%)$ in the $\mathrm{aFSL}^{+}$ $\operatorname{group}(P<0.01)$. Sixteen patients $(9.2 \%)$ in the FSGS $^{+}$ group reached the ESRD outcome compared with 9 patients $(2.4 \%)$ in the $\mathrm{FSL}^{-}$group $(P<0.001)$ and 2 patients (1.2\%) in the $\mathrm{aFSL}^{+}$group $(P<0.01)$. Nine patients $(2.4 \%)$ in the $\mathrm{FSL}^{-}$group reached the all-cause death outcome compared with 9 patients $(5.2 \%)$ in the FSGS $^{+}$group and 6 patients $(3.7 \%)$ in the aFSL ${ }^{+}$group.

The IMN patients with FSGS had a significantly higher risk of progressing to the primary outcome and ESRD outcome compared with patients in the other groups (Fig. 2). The IMN patients with FSGS also had a significantly higher risk of progressing to the all-cause death outcome compared with the $\mathrm{FSL}^{-}$groups, while the $\mathrm{FSGS}^{+}$group and $\mathrm{aFSL}^{+}$group had no significant difference (Fig. 3). At the 24-months follow-up point, the event-free survival for primary outcome in the FSGS $^{+}$ groups was $84.2 \pm 3.5 \%$, compared with $99.4 \pm 0.6 \%$ in the $\mathrm{aFSL}^{+}$group and $97.2 \pm 1.1 \%$ in the $\mathrm{FSL}^{-}$group.

The patients with NOS, tip variant and collapsing variant had a higher ratio of progression to the primary outcome (Fig. 4a), and those with NOS, and tip variant had a higher ratio of progression to ESRD (Fig. 4b) and a numerically higher ratio of progression to all-cause death (Fig. 4c).

\section{Discussion}

Focal segmental lesions, including typical FSGS lesions and atypical focal segmental lesions, are common in IMN. The percentage of IMN patients with FSGS lesions ranges widely different, and the predictive value of FSGS for worse renal outcome in IMN patients remains debated. In this retrospective IMN cohort from a single Chinese centre, we attempted to differentiate atypical FSL, named aFSL, from typical FSGS. Patients with aFSL, along with patients without FSL, had a better outcome with respect to progression to the primary outcome. In the current study, focal segmental glomerulosclerosis, excluding the atypical lesion, is a predictor of ESRD or eGFR decline of $\geq 50 \%$ of baseline eGFR in patients with idiopathic membranous nephropathy.

In 2004, D'Agati proposed a working classification of FSGS, including five types of lesions [9]. However, some segmental lesions, named aFSL by the present authors, comprising synechia, capillary shrinking, and GBM thickening involving the segmental glomerular tuft, which are unaccompanied by any typical FSGS lesion, were not included in the 2004 classification. Ehrenreich and Churg first reported focal sclerosis lesions in 30\% of cases of $\mathrm{MN}$ [3]. The percentage of $\mathrm{FSGS}^{+}$in IMN differed significantly in later studies (Table 4), different 


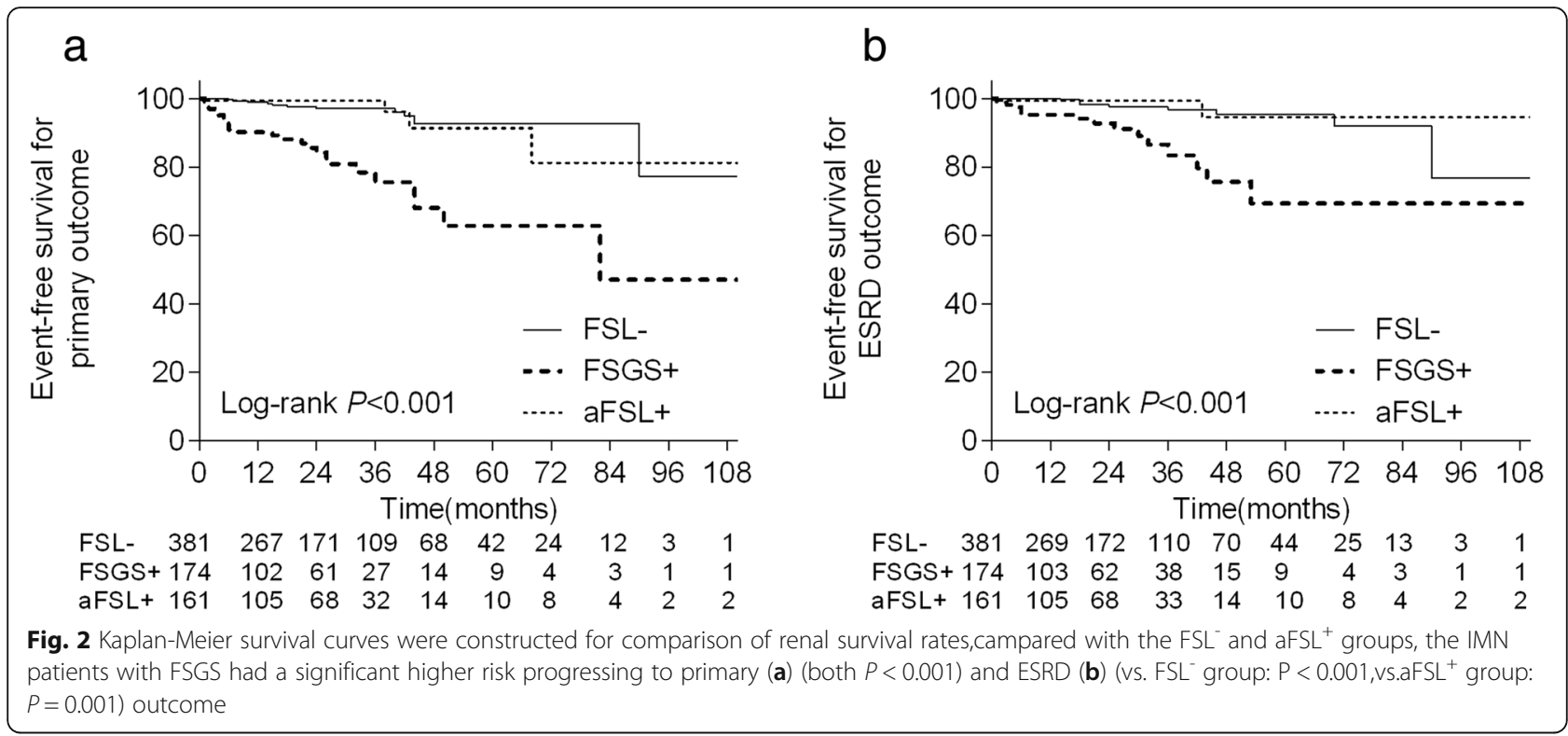

definitions in clinical practice may be one of the most important reasons. The present study attempts to separate aFSL from FSGS in IMN.

In an animal model, Wharram found that 21 to $40 \%$ depletion of podocytes showed capsular adhesions, mesangial expansion, and FSGS, and a $>40 \%$ depletion showed segmental-to-global glomerulosclerosis [21]. Subepithelial immune deposits may contribute to disrupting the podocyte attachment to the GBM [7],and the detachment of the epithelium may lead to focal sclerosis [4]. Gupta supported the hypothesis of glomerular hyperperfusion and hyperfiltration as one of the causative mechanisms in the development of FSGS in IMN [19]. Moritare ported that glomerular capillary

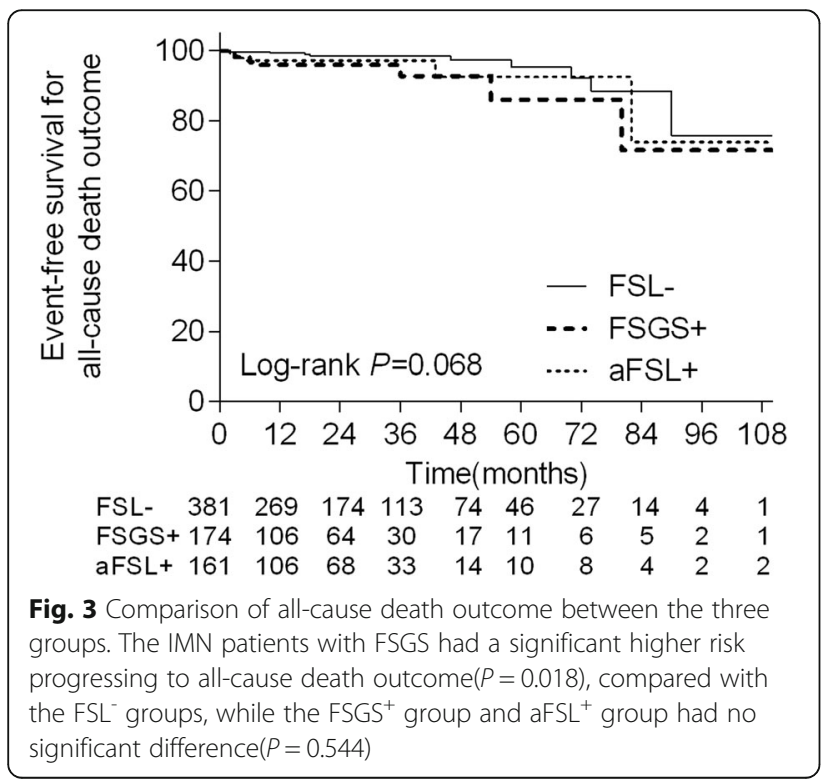

injury was more prominent in MN combined with FSGS and that possible mechanisms of glomerular capillary injury included glomerular hypertrophy, decreased VEGF expression of podocytes, and thickening of glomerular capillary walls [20]. Previous studies have shown that morphological FSGS lesions in preeclampsia and malignant hypertension are likely mediated by the combination of glomerular endothelial cell injury and podocyte injury $[22,23]$. Daehn indicated that endothelial mitochondrial oxidative stress determines podocyte depletion in segmental glomerulosclerosis, and segmental glomerulosclerosis, which develops as a result of podocyteendothelial crosstalk [24].

The segmental podocyte disease and proliferation of the matrix may be considered a progression to FSGS in IMN, and this progression is reversible if appropriate measures are taken. If detachment or damage of the podocyte persists and deteriorates, aFSL may progress irreversibly to FSGS and renal injury. However, the synechia lesions may arise through physical stress placed on the tuft in the setting of severe nephrotic syndrome by the flux of protein-rich filtrate towards the tubular pole. This process is similar to that in the tip lesion of primary FSGS [25]. The phenomenon comprising high proteinuria and low levels of serum albumin was observed in IMN patients with aFSL, which supports this assumption. Smeets also reported that lesions detected by parietal epithelial cell markers were small and often located close to the glomerular tip in primary FSGS [26].

Unlike most previous studies that excluded patients followed up for less than 12 months $[7,11]$ or 6 months [13], the present study included patients followed up from 1 to 12 months,. This enrolment method was based on the finding that 10 of 24 patients died and 16 of 44 patients 


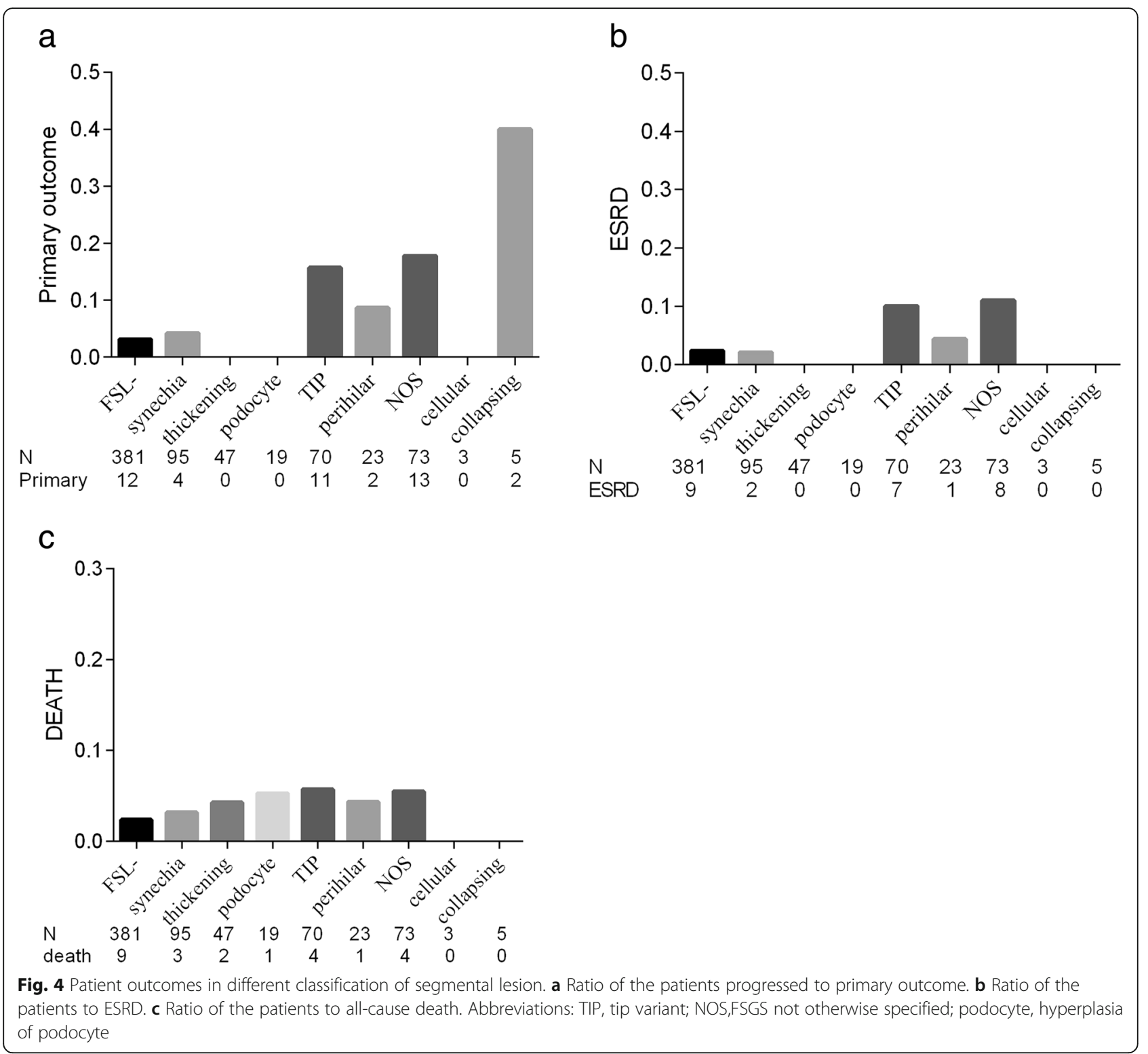

Table 4 Percentage of IMN patients with FSGS+ in the literature

\begin{tabular}{lll}
\hline Author & Percentage of FSGS (\%) & Year of publication \\
\hline Van Damme B et al. [4] & 33 (FSSH), 53(adhesion) & 1990 \\
Dumoulin A et al. [7] & 41.7 & 2003 \\
Shiiki H et al. [10] ${ }^{a}$ & 5.0 & 2004 \\
Heeringa SF et al. [12] & 41.5 & 2007 \\
Gupta R et al. [19] & 12.8 & 2010 \\
Sprangers B et al. [13] & 20.5 & 2012 \\
Chen Y et al. [15] & 10.1 & 2014 \\
Morita M et al. [20] & 10.4 & 2015 \\
Gu QH et al. [14] & 2.5 & 2016 \\
Present study & $22.5(\mathrm{aFSL}), 24.3(F S G S)$ & $/$
\end{tabular}

Abbreviations: FSSH Focal and segmental sclerosis and hyalinosis, aFSL Atypical focal segmental lesion; ${ }^{\text {PPresent }}$ in $\geq 20 \%$ of total glomeruli; progressed to the primary outcome within the first 6 months in our study. Consistent with previous research, in the present analysis, older age [10, 15], hypertension [13], eGFR at biopsy [10, 12, 13, 15, 27, 28], FSGS [4, 7, 8, 15], chronic tubulointerstitial injury $[8,10,15,27-30]$, global Glomerulosclerosis [10], and vascular lesion $[7,8]$ were predictors of IMN progression to ESRD or eGFR decline of $>50 \%$ of baseline eGFR, or doubling of creatinine. In some previous studies, the FSGS lesion in IMN seemed to have a limited predictive value; when combined with clinical and other pathological parameters, it did not emerge as an independent prognostic factor for the decline in renal function $[11,12]$, which was consistent with our observations in the model 1 mutivariate analysis. However, we noticed that the reported percentage of IMN patients with FSGS lesions differs significantly between studies, and we found that after 
excluding the atypical lesion, FSGS lesion was an independent predictive factor in IMN for progression to a $50 \%$ decline in the initial estimated glomerular filtration rate or ESRD in the current study.

There were some limitations to this study. First, an accurate definition of aFSL is still debated, and the adhesion and hyperplasia of podocytes may emerge as different mechanisms. However, the classification used in this study stressed the characteristics differentiating atypical FSL from typical FSGS in IMN. Second, this study used a retrospective design, and the effect of confounding factors could not be fully excluded. Some important baseline covariates may also not have been equally distributed. Third, this analysis relied on data from a single centre. Moreover, a longer follow-up duration could have better validated our findings, and the patients who were lost to follow-up could have affected this study's outcomes. Data over time, such as change in proteinuria as a prognostic factor, could not easily be obtained in this retrospectively studied population.

\section{Conclusions}

Histopathologic findings tubulointerstitial fibrosis area $\geq 15 \%$ and FSGS at biopsy were independent risk factors for the primary outcome, even when combined with clinical parameters. Focal segmental lesions in IMN were common in the present study, which is the first, to our knowledge, to differentiate aFSL from FSGS in IMN and to show that FSGS, excluding the aFSL, was an independent predictor for a $50 \%$ decline in initial eGFR or ESRD.

\section{Abbreviations \\ ACE: Angiotensin-Iconverting enzyme; aFSL: Atypical focal segmental lesions; $\mathrm{Cl}$ : Confidence interval; CKD: Chronic Kidney Disease; eGFR: Estimated glomerular filtration rate; ESRD: End stage renal disease; FSGS: Focal segmental glomerulosclerosis; FSL-: Without focal segmental lesions; HR: Hazard ratio; IMN: Idiopathic membranous nephropathy; KDIGO: Kidney disease improving global outcomes}

\section{Acknowledgements}

Not applicable.

\section{Authors' contributions}

HGH participated in data acquisition, analysis, definition of the atypical focal segmental lesions in MN, interpretation and wrote the first draft of the manuscript. WY and QRY performed the histological examination of the kidney. CZ, YYH, and SWL participated in data acquisition. CQW, KY, and XMP made substantial contributions to conception and design. All authors read and approved the final manuscript.

\section{Funding}

This work was supported by the Guangxi Zhuang Autonomous Region Health and Family Planning Commission Foundation (Z2016627), Key R\&D Program of Guangxi Zhuang Autonomous Region (AB16380229) and National Natural Science Foundation of China (81260121). The funders had no role in study design, collection, analysis, interpretation of data, writing the report, nor in the decision to submit the report for publication.

\section{Availability of data and materials}

The datasets used during the current study are available from the corresponding author on reasonable request.

\section{Ethics approval and consent to participate}

This study was approved by the institutional review board at the People's Hospital of Guangxi Zhuang Autonomous Region (No. 20160302), and the need for informed consent from the patients was waived because of the retrospective study design. All clinical investigations were conducted in accordance with the guidelines of the 2008 Declaration of Helsinki.

\section{Consent for publication}

Not applicable.

\section{Competing interests}

The authors declare that they have no competing interests.

\section{Author details}

'Department of Nephrology, The People's Hospital of Guangxi Zhuang Autonomous Region, 6 Taoyuan Road, Qingxiu District, Nanning 530000, China. ${ }^{2}$ Department of Pathology, The People's Hospital of Guangxi Zhuang Autonomous Region, 6 Taoyuan Road, Qingxiu District, Nanning 530000, China.

Received: 17 October 2017 Accepted: 29 July 2019

Published online: 22 August 2019

\section{References}

1. Haas M, Meehan SM, Karrison TG, Spargo BH. Changing etiologies of unexplained adult nephrotic syndrome: a comparison of renal biopsy findings from 1976-1979 and 1995-1997. Am J Kidney Dis. 1997;30:621-31.

2. Pan $X, X u J$, Ren $H$, Zhang $W, X u Y$, Shen $P$, et al. Changing spectrum of biopsy-proven primary glomerular diseases over the past 15 years: a single center study in China. Contrib Nephrol. 2013;181:22-30.

3. Ehrenreich T, Churg J. Focal sclerosis in membranous nephropathy. Am J Pathol. 1977:86:37A abstr.

4. Van Damme B, Tardanico R, Vanrenterghem Y, Desmet V. Adhesions, focal sclerosis,protein crescents, and capsular lesions in membranous nephropathy. J Pathol. 1990;161:47-56.

5. Iwahashi C. Clinico-pathological study of focal glomerular sclerotic lesions in idiopathic membranous nephropathy. Nippon Jinzo Gakkai Shi. 1991;33:139-43.

6. Wakai S, Magil AB. Focal glomerulosclerosis in idiopathic membranous glomerulonephritis. Kidney Int. 1992;41:428-34.

7. Dumoulin A, Hill GS, Montseny JJ, Meyrier A. Clinical and morphological prognostic factors in membranous nephropathy: significance of focal segmental glomerulosclerosis. Am J Kidney Dis. 2003;41:38-48.

8. Yoshimoto K, Yokoyama H, Wada T, Furuichi K, Sakai N, Iwata Y, et al. Pathologic findings of initial biopsies reflect the outcomes of membranous nephropathy. Kidney Int. 2004;65:148-53.

9. D'Agati VD, Fogo AB, Bruijn JA, Jennette JC. Pathologic classification of focal segmental glomerulosclerosis: a working proposal. Am J Kidney Dis. 2004;43:368-82.

10. Shiiki H, Saito T, Nishitani Y, Mitarai T, Yorioka N, Yoshimura A, et al. Prognosis and risk factors for idiopathic membranous nephropathy with nephrotic syndrome in Japan. Kidney Int. 2004;65:1400-7.

11. Troyanov S, Roasio L, Pandes M, Herzenberg AM, Cattran DC. Renal pathology in idiopathic membranous nephropathy:a new perspective. Kidney Int. 2006;69:1641-8.

12. Heeringa SF, Branten AJ, Deegens JK, Steenbergen E, Wetzels JF. Focal segmental glomerulosclerosis is not a sufficient predictor of renal outcome in patients with membranous nephropathy. Nephrol Dial Transplant. 2007;22:2201-7.

13. Sprangers B, Bomback AS, Cohen SD, Radhakrishnan J, Valeri A, Markowitz GS, et al. Idiopathic membranous nephropathy: clinical and histologic prognostic features and treatment patterns over time at a tertiary referral center. Am J Nephrol. 2012;36:78-89.

14. Gu QH, Cui Z, Huang J, Zhang YM, Qu Z, Wang F, et al. Patients with combined membranous nephropathy and focal segmental glomerulosclerosis have comparable clinical and autoantibody profiles with primary membranous nephropathy. Medicine (Baltimore). 2016;95(21):e3786. 
15. Chen Y, Tang L, Feng Z, Cao X, Sun X, Liu M, et al. Pathological predictors of renal outcomes in nephrotic idiopathic membranous nephropathy with decreased renal function. J Nephrol. 2014;27:307-16.

16. Zheng CX, Chen ZH, Zeng CH, Qin WS, Li LS, Liu ZH. Triptolide protects podocytes from puromycinaminonucleoside induced injury in vivo and in vitro. Kidney Int. 2008;74:596-612.

17. Levey AS, Stevens LA, Schmid CH, Zhang YL, Castro AF 3rd, Feldman Hl, et al. CKD-EPI (chronic kidney disease epidemiology collaboration). A new equation to estimate glomerular filtration rate. Ann Intern Med. 2009;150:604-12.

18. Kidney Disease: Improving Global Outcomes (KDIGO) CKD Work Group. KDIGO 2012 clinical practice guideline for the evaluation and management of chronic kidney disease. Kidney Int Suppl. 2013;3:1-150.

19. Gupta R, Sharma A, Mahanta PJ, Jacob TG, Agarwal SK, Roy TS, et al. Focal segmental glomerulosclerosis in idiopathic membranous glomerulonephritis: a clinico-pathological and stereological study. Nephrol Dial Transplant. 2010;25:444-9.

20. Morita M, Mii A, Shimizu A, Yasuda F, Shoji J, Masuda Y, et al. Glomerular endothelial cell injury and focal segmental glomerulosclerosis lesion in idiopathic membranous nephropathy. PLoS One. 2015;10(4):e0116700.

21. Wharram BL, Goyal M, Wiggins JE, Sanden SK, Hussain S, Filipiak WE, et al. Podocyte depletion causes glomerulosclerosis: diphtheria toxin-induced podocyte depletion in rats expressing human diphtheria toxin receptor transgene. J Am Soc Nephrol. 2005;16:2941-52.

22. Nochy D, Heudes D, Glotz D, Lemoine R, Gentric D, Bruneval P, et al. Preeclampsia associated focal and segmental glomerulosclerosis and glomerular hypertrophy: a morphometric analysis. Clin Nephrol. 1994:42:9-17.

23. Nishimoto K, Shiiki H, Nishino T, Kimura T, Sasaki Y, Yamasaki M, et al. Glomerular hypertrophy in preeclamptic patients with focal segmental glomerulosclerosis. A morphometric analysis. ClinNephrol. 1999;51:209-19.

24. Daehn I, Casalena G, Zhang T, Shi S, Fenninger F, Barasch N, et al. Endothelial mitochondrial oxidative stress determines podocyte depletion in segmental glomerulosclerosis. J Clin Invest. 2014;124:1608-21.

25. Howie AJ, Ferreira MA, Majumdar A, Lipkin GW. Glomerular prolapse as precursor of one type of segmental sclerosing lesions. J Pathol. 2000;190:478-83.

26. Smeets B, Stucker F, Wetzels J, Brocheriou I, Ronco P, Gröne HJ, et al. Detection of activated parietal epithelial cells on the glomerular tuft distinguishes early focal segmental glomerulosclerosis from minimal change disease. J Am J Pathol. 2014;184:3239-48.

27. Zuo K, Wu Y, Li SJ, Xu F, Zeng CH, Liu ZH. Long-term outcome and prognostic factors of idiopathic membranous nephropathy in the Chinese population. Clin Nephrol. 2013;79:445-53.

28. Eriguchi M, Oka H, Mizobuchi T, Kamimura T, Sugawara K, Harada A. Long-term outcomes of idiopathic membranous nephropathy in Japanese patients treated with low-dose cyclophosphamide and prednisolone. Nephrol Dial Transplant. 2009;24:3082-8.

29. Paraskevakou H, Kavantzas N, Pavlopoulos PM, Voudiklari S, Zerefos N, Papagalanis N, et al. Membranous glomerulonephritis: a morphometric study. Pathol Res Pract. 2000;196:141-4.

30. Horvatic I, Ljubanovic DG, Bulimbasic S, Knotek M, Prkacin I, Tisljar M, et al. Prognostic significance of glomerular and tubulointerstitial morphometry in idiopathic membranous nephropathy. Pathol Res Pract. 2012;208:662-7.

\section{Publisher's Note}

Springer Nature remains neutral with regard to jurisdictional claims in published maps and institutional affiliations.

Ready to submit your research? Choose BMC and benefit from:

- fast, convenient online submission

- thorough peer review by experienced researchers in your field

- rapid publication on acceptance

- support for research data, including large and complex data types

- gold Open Access which fosters wider collaboration and increased citations

- maximum visibility for your research: over $100 \mathrm{M}$ website views per year

At BMC, research is always in progress.

Learn more biomedcentral.com/submissions 